Division of Infectious Diseases and General Internal Medicine, Sunnybrook Health Sciences Centre, Toronto, Ontario, Canada

2 Department of Medicine, University of Toronto, Toronto, Ontario, Canada

3 Institute of Health Policy, Management \& Evaluation, Dalla Lana School of Public Health, Faculty of Medicine, University of Toronto, Toronto, Ontario, Canada

4 Department of Family Medicine, McGill University, Montreal, Quebec, Canada

5 Division of Pediatric Emergency Medicine, The Hospital for Sick Children, Toronto, Ontario, Canada; Department of Pediatrics, University of Toronto, Toronto, Ontario, Canada

6 Centre for Quality Improvement and Patient Safety, University of Toronto, Toronto, Ontario, Canada

7 Department of Family Medicine, Markham Stouffville Hospital, Markham, Ontario, Canada; Department of Family \& Community Medicine, University of Toronto, Toronto, Ontario, Canada

8 Quality of Care NL/Choosing Wisely NL, Memorial University of Newfoundland, St. John's, Newfoundland, Canada

Correspondence to JA Leis jerome.leis@sunnybrook.ca Cite this as: BMJ 2020;371:m4125 http://dx.doi.org/10.1136/bmj.m4125 Published: 13 November 2020

PRACTICE POINTER

\title{
Using antibiotics wisely for respiratory tract infection in the era of covid-19
}

Jerome A Leis, ${ }^{1,2,3,6}$ Karen B Born, ${ }^{3}$ Guylene Theriault, ${ }^{4}$ Olivia Ostrow, ${ }^{5,6}$ Allan Grill, ${ }^{7}$ K Brian Johnston ${ }^{8}$

\section{What you need to know}

- Most acute respiratory tract infections (RTIs) are viral and can be managed through virtual care

- For patients with RTI symptoms who test negative for covid-19, a diagnosis of viral RTI remains most likely, and supportive management can continue to be offered virtually in most cases

- Virtual assessments limit diagnostic capabilities and can lead to overprescribing of unnecessary antibiotics. For those RTIs that may be bacterial, arrange an in-person assessment where possible to confirm the diagnosis (eg, to assess the tympanic membrane, to perform a test for Group A streptococcus, or to obtain a chest radiograph)

A 68 year old woman with history of chronic hypertension and type 2 diabetes calls her doctor's office about a three day history of productive cough and fever. She is booked for an initial virtual visit with her doctor, who determines that she is not acutely unwell or short of breath and probably has viral bronchitis.

The doctor gives her a "viral prescription" (supportive management)by phone to help manage her symptoms, sends her for a nasopharyngeal swab for covid-19, and asks her to follow up within 48 hours if needed or any time if symptoms worsen. The next day, the woman calls because her symptoms are worse. She has received a negative test result for covid-19. An in-person assessment is booked to exclude bacterial pneumonia.

Unnecessary prescriptions of antibiotic medication result in preventable adverse drug reactions and are driving antimicrobial resistance-an international public health threat. Nearly half of all outpatient antibiotics are intended to treat respiratory tract infection (RTI), even though one third to half of these are inappropriately prescribed for patients without a bacterial respiratory infection.

Before the covid-19 pandemic, international efforts such as the Choosing Wisely campaigns had focused on advancing improved antibiotic prescribing practices for the management of RTI (box 1). In the era of covid-19, primary care delivery has been disrupted, and many clinicians have shifted to virtual care whenever possible, especially when supplies of personal protective equipment are limited. ${ }^{2}$ Clinicians who provide primary care are faced with challenging questions in the management of RTI, including when a patient should be tested for SARS-CoV-2, the virus that causes covid-19, when to prescribe antibiotics, and when a patient should be assessed in person. More than ever, a standardised approach is needed that is informed by best available evidence and promotes the judicious use of antibiotics for RTI.

\section{Box 1: Choosing Wisely campaigns}

- Choosing Wisely is a clinician-led campaign, present in more than 20 countries, which encourages conversations between clinicians and patients about overuse of antibiotic medication. Below is a sample of statements from different countries' Choosing Wisely campaigns pertaining to avoiding antibiotics for viral respiratory tract infection.

- “Don't use antibiotics for upper respiratory infections that are likely viral in origin, such as influenza-like illness, or self-limiting, such as sinus infections of less than seven days of duration" (College of Family Physicians of Canada, Choosing Wisely Canada).

- "Avoid prescribing antibiotics for upper respiratory infections" (Infectious Diseases Society of America, Choosing Wisely, United States).

- "Avoid prescribing antibiotics for upper respiratory tract infection." (Australasian Society for Infectious Diseases, Choosing Wisely Australia).

\section{What is best practice?}

Table 1 summarises when patients should be assessed in person and when to prescribe antibiotics based on best available evidence related to RTI in primary care. ${ }^{5-9}$ Among patients presenting with signs or symptoms compatible with covid-19, whether suspected or confirmed, most will have a mild self-limited illness that improves within a few days or up to two weeks. ${ }^{3}$ A systematic review of patients with covid-19 showed that even among the most critically ill, incidence of secondary bacterial infection is extremely low. ${ }^{4} \mathrm{~A}$ patient with RTI who is covid-19 negative usually still has a non-bacterial cause for their symptoms. ${ }^{1}$ 
Table 1| Proposed approach for when to conduct virtual versus in-person assessment of outpatients with RTI in the era of covid-19, and the role of antibiotics based on best available evidence

\begin{tabular}{|c|c|c|c|}
\hline & Virtual visit & In-person visit & Role of antibiotics \\
\hline $\begin{array}{l}\text { Covid-19, influenza, or other influenza-like } \\
\text { illness }\end{array}$ & $\begin{array}{c}\text { • Fever } \\
\text { - Respiratory symptoms } \\
\text { - No shortness of breath }\end{array}$ & $\begin{array}{l}\text { - Shortness of breath or hypoxia (if } \\
\text { monitoring available) } \\
\text { - Concerns of dehydration } \\
\text { - Other red flags present* }\end{array}$ & No role in outpatient setting 34 \\
\hline Acute otitis media & $\begin{array}{c}\cdot \text { Symptoms }<48 \text { hours } \\
\bullet \text { Fever }<39^{\circ} \mathrm{C} \\
\text { - Pain controlled with oral pain medication } \\
\bullet \text { Appearing well }\end{array}$ & $\begin{array}{l}\text { - Symptoms }>48 \text { hours despite adequate } \\
\text { pain medications } \\
\bullet \text { Fever } \geq 39^{\circ} \mathrm{C} \\
\bullet \text { Looks ill }\end{array}$ & $\begin{array}{c}\text { Any in-person criteria met AND exam showing } \\
\text { bulging tympanic membrane or a perforated } \\
\text { tympanic membrane with purulent discharge. } \\
\text { Otherwise, reassess within } 24-48 \text { hours or use } \\
\text { delayed prescription if patient unable to access } \\
\text { an in-person reassessment }{ }^{5}\end{array}$ \\
\hline Pharyngitis & $\begin{array}{l}\bullet \text { Mild symptoms } \\
\bullet<48 \text { hours } \\
\text { - Low suspicion for bacterial pharyngitis, } \\
\text { eg, age }>15 \text {, no fever, presence of cough or } \\
\text { runny nose }\end{array}$ & $\begin{array}{l}\text { - Persistent or worsening symptoms >48 } \\
\text { hours } \\
\text { - High suspicion of bacterial pharyngitis }\end{array}$ & $\begin{array}{l}\text { Any in-person criteria met to apply clinical } \\
\text { predictive score to determine need for throat } \\
\text { swab. Antibiotics only if positive culture or rapid } \\
\text { test for Group A streptococcus in a patient with } \\
\text { moderate to high likelihood based on validated } \\
\text { predictive score } \\
\text { pre }\end{array}$ \\
\hline Sinusitis & $\begin{array}{l}\cdot \text { Mild symptoms } \\
\bullet<7 \text { days } \\
\text { - No red flags** }\end{array}$ & $\begin{array}{l}\text { - No improvement despite }>7 \text { days } \\
\text { • Presence of red flags }{ }^{\star \star}\end{array}$ & $\begin{array}{l}\text { Any in-person criteria met AND either severe } \\
\text { symptoms or no improvement with a } 72 \text { hour } \\
\text { trial of nasal corticosteroids }{ }^{8} \text { Delayed } \\
\text { prescription may be given when initiating nasal } \\
\text { corticosteroid if patient unable to access an } \\
\text { in-person reassessment }\end{array}$ \\
\hline $\begin{array}{l}\text { Exacerbation of chronic obstructive pulmonary } \\
\text { disease }\end{array}$ & $\begin{array}{l}\text { - Patient is able to do their activities of } \\
\text { daily living } \\
\text { - Patient is able to seek urgent } \\
\text { reassessment as needed }\end{array}$ & $\begin{array}{l}\text { - Patient is too short of breath to do their } \\
\text { activities of daily living }\end{array}$ & $\begin{array}{c}\text { Only if there is a clear increase in sputum } \\
\text { purulence AND either increase in sputum } \\
\text { volume and/or increased dyspnoea. Virtual or } \\
\text { in-person assessment can be used }\end{array}$ \\
\hline Suspected pneumonia & - Not an option & $\begin{array}{l}\text { - If pneumonia is suspected, clinical } \\
\text { assessment and chest radiograph } \\
\text { recommended }\end{array}$ & $\begin{array}{c}\text { Only for patient with compatible presentation } \\
\text { and pneumonia present on chest radiograph. } \\
\text { Patients with no vital sign abnormalities and a } \\
\text { normal respiratory examination are unlikely to } \\
\text { have pneumonia and often do not need a chest } \\
\text { radiograph9 }\end{array}$ \\
\hline Common cold & $\begin{array}{l}\text { - High fever controllable with fever } \\
\text { medication } \\
\bullet \text { Cough } \\
\bullet \text { Congestion } \\
\bullet \text { Body aches } \\
\text { - Sometimes mild gastrointestinal } \\
\text { symptoms }\end{array}$ & $\begin{array}{l}\text { - Concerns of dehydration } \\
\text { - Presence of red flags* }\end{array}$ & No role for antibiotics \\
\hline
\end{tabular}

${ }^{*}$ Red flags for patient with viral infection: for children may include fast breathing or trouble breathing, bluish lips or face, ribs pulling in with each breath, chest pain, child refuses to walk, signs of dehydration, history of seizure, any fever in child less than 12 weeks old. In adults may include difficulty breathing or shortness of breath, acute chest pain or abdominal pain, dizziness, confusion, or functional decline.

${ }^{\star *}$ Red flags for patient with sinusitis include altered mental status, headache, systemic toxicity, swelling of the orbit, double vision, change in visual acuity, neurologic deficits.

Figure 1 outlines an approach to assessment and management of patients presenting with RTI based on their clinical presentations (based on table 1) and whether their symptoms and testing results are compatible with covid-19. Virtual care modalities can include synchronous (audio/video) and asynchronous (secure messaging) communication between physician and patients. These modalities are effective in communication regarding issues such as symptom management, potential treatment approaches, and test results; however, they may limit proper assessment and diagnosis. ${ }^{11}$ Most RTI syndromes are viral and can still be diagnosed and managed using virtual care. Conversely, bacterial RTI infections, which are the exception, generally require an in-person assessment to make an accurate diagnosis. For example, acute otitis media requires on otoscopic examination showing either a bulging tympanic membrane or a perforated tympanic membrane with purulent discharge. ${ }^{5}$ Acute bacterial pharyngitis requires isolation of Group A itreptococcus by culture or rapid testing, which should only be performed based on a validated predictive score that incorporates examination of the oropharynx and cervical nodes. ${ }^{6} \mathrm{~A}$ chest radiograph is required to diagnose bacterial pneumonia, because antibiotics based on history or examination alone will result in overtreatment. ${ }^{9}$ Finally, most sinusitis is viral, therefore bacterial sinusitis should only be considered among patients with at least seven days of symptoms who are having severe symptoms without improvement following trial of nasal corticosteroids. ${ }^{7}$ 


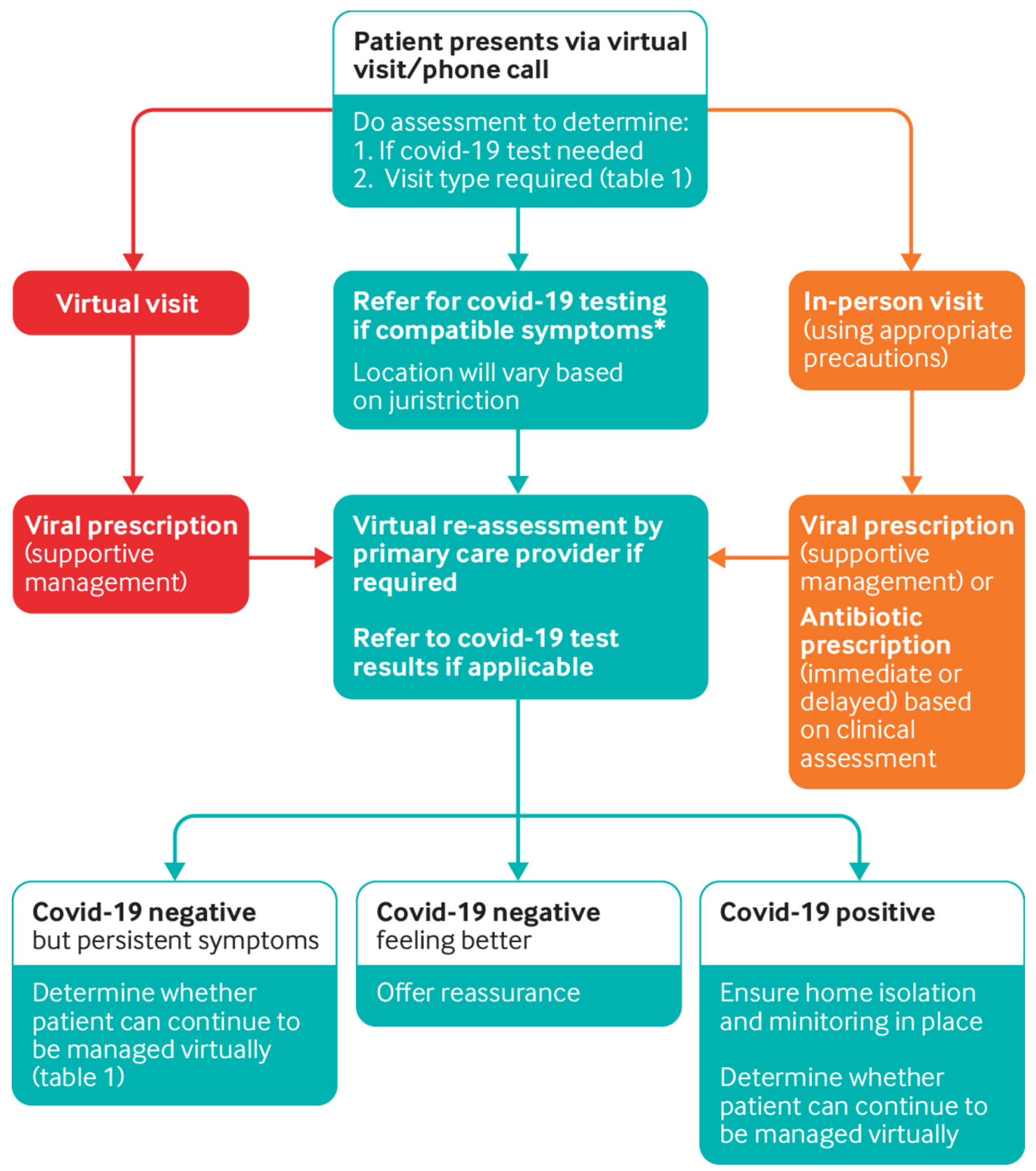

* Covid-19 compatible symptoms

Most common symptoms: fever, dry cough, tiredness

Less common symptoms: aches and pains, sore throat, diarrhoea, conjunctivitis,

headache, loss of taste or smell, a rash on skin, or discolouration of fingers and toes

Fig 1 | Proposed management of respiratory tract infection (RTI) in the era of virtual care and covid-19. Adapted from Choosing Wisely Canada ${ }^{10}$

\section{What are the barriers to judicious antibiotic prescribing?}

The switch to virtual care may be a barrier to judicious prescribing of antibiotics for RTI during the covid-19 pandemic. Two retrospective studies that examined administrative databases found that the delivery of care virtually is associated with less diagnostic testing and more empiric antibiotic prescribing than in-person 
primary care. ${ }^{12} 13$ Before the covid-19 pandemic, multiple other factors were known to be associated with unnecessary antibiotic prescribing for RTI. A systematic review of factors associated with antibiotic prescribing for RTI specifically identified 28 studies assessing predictors of antimicrobial use. ${ }^{14}$ Patient expectation for antibiotics was not associated with antibiotic prescribing (adjusted odds ratio 0.6-9.9), whereas the clinician's perception that the patient or parent was expecting an antibiotic treatment was far more predictive (aOR 2.1-23.3). The role of physician perceptions of patient expectation for antibiotics in prescribing practices has suggested a need for communication strategies that physicians can use in navigating the clinical encounter with a patient. Time constraints associated with having such discussions with patients about why antibiotics are unnecessary are often cited as a barrier by clinicians. However, studies in both paediatric and adult patient populations show that these conversations do not substantially prolong visit duration compared with prescribing an antibiotic. ${ }^{15}$ Evaluation is limited regarding similar barriers in telemedicine and how the virtual clinical interaction affects conversations regarding unnecessary antibiotics. ${ }^{11} 16$

\section{What is the patient perspective?}

Patients and family members are not necessarily seeking an antibiotic, but do want clear information about diagnosis, reassurance, safety net advice, and a treatment plan. ${ }^{17}$ This remains true in the era of covid-19, where many patients may be feeling heightened anxiety associated with the onset of RTI symptoms. Limited public awareness about the differences between a viral and bacterial infection alongside beliefs that antibiotics are low risk medications are drivers of unnecessary prescriptions in the outpatient setting. ${ }^{18}$ Patients and the general public are more receptive to communication that stresses the effect of antibiotic overuse on the individual, rather than harms to society.

\section{How to improve practice}

Making a practice change in antibiotic prescribing for RTI is not as much about knowing the right thing to do, as it is integrating the right evidence based clinical tools that support best practice. In cases without diagnostic uncertainty (for example, a positive test result for covid-19, or a clear alternative non-bacterial RTI diagnosis), clinicians should be able to avoid antibiotics completely by using structured communication that provides diagnostic clarity, identifies and addresses specific patient concerns, and offers a contingency plan. ${ }^{217} \mathrm{Box} 2$ describes how to have these discussions with a patient.

Box 2: Examples of communication strategies for clinicians to use with a patient with a suspected viral RTI to promote judicious use of antibiotics

- Provide diagnostic clarity

o You have a sinus infection which is nearly always caused by a virus

o Your test is positive for covid-19. Most cases are mild and resolve without needing to visit the hospital

o Your test is negative for covid-19; however, you are experiencing similar symptoms such as a runny nose, fever, and fatigue. This is likely viral

- Identify and address patient concerns

o I know that in the past you have been prescribed antibiotics for these symptoms, but antibiotics will not help this infection resolve more quickly or help you feel better o These infections can be quite bothersome. What specific symptoms are bothering you most?

o I know that you are concerned about covid-19. A negative test means there was no virus that could be detected on the day you were tested. Even though you are starting to feel better and your test is negative, please continue to self-isolate until your symptoms have significantly improved

- Offer a symptom management plan

o To help with your nasal congestion, you could use nasal saline

o For a sore throat use ice chips, throat lozenges or spray, or gargle with salt water

- o For fever and pain relief, use over-the-counter medications such as paracetamol or ibuprofen

- Offer a safety net or contingency plan

- o You may experience symptoms associated with the covid-19 virus for up to two weeks and sometimes longer. Watch out for shortness of breath or difficulty breathing and seek urgent medical attention if this develops

o Symptoms from your sinus infection can last 7-14 days but should begin to improve by day seven

- o If your symptoms are getting worse rather than improving, please call or access other services to be reassessed

In cases where a bacterial cause of infection is uncertain, such as acute otitis media or occasionally sinusitis, a delayed prescription can be used. The delayed prescription has been widely adopted in the UK and Spain. It involves a post-dated antibiotic prescription with instruction to fill the prescription only if symptoms do not improve. Since most patients have a self-limiting viral infection, fewer than one-third of patients fill the delayed prescription. ${ }^{19}$ Delayed prescriptions should not be used routinely for other suspected viral diagnoses, especially in the era of covid-19 where symptoms are expected to take up to 1-2 weeks to fully resolve.

A "viral prescription" is another tool that is increasingly used in Canada for any patient with suspected viral infection, although it has undergone limited evaluation to date. ${ }^{20} \mathrm{~A}$ viral prescription is a prescription pad outlining the diagnosis, why an antibiotic was not prescribed, symptom management, and evidence based supportive therapies, as well as a contingency plan should symptoms persist. $^{17}$

The use of these tools can move the conversation away from antibiotic prescribing towards syndrome guided management of RTI and supporting shared decision making. ${ }^{21}$ These tools are often coupled with broader education and health literacy efforts to educate patients about antibiotic overuse through posters and plain language information. The covid-19 pandemic offers an opportunity to advance clinician practices and patient acceptability and health literacy regarding symptom management strategies and avoidance of antibiotics, given broad public interest and heightened awareness of viral respiratory infections.

\section{Patient outcome}

In-person assessment of the woman with cough and fever revealed coarse crackles and expiratory wheezes, but chest radiography showed no evidence of pneumonia. The doctor explained the diagnosis of viral bronchitis and prescribed a bronchodilator, reinforced the principles of supportive therapy, and offered a follow-up visit in three days if she had not improved. By day seven of illness she was feeling better and decided that no follow-up was required. 


\section{Education into practice}

- If you are frequently prescribing antibiotics after virtual assessments for patients with RTI, you may be overprescribing. For patients with viral RTIs, how might you adopt an approach that addresses patients' concerns and expectations by offering diagnosis, symptom management strategies, and a contingency plan in case symptoms worsen?

- If you suspect a bacterial RTI, can you conduct an in-person assessment using the appropriate precautions, to confirm the diagnosis prior to prescribing antibiotics?

\section{How patients were involved in the creation of this article}

Brian Johnston, a co-author on this article, is a patient and adviser with Quality of Care Newfoundland. He has been involved in numerous research projects and activities related to the Choosing Wisely Canada campaign in Newfoundland, Canada. He has a special interest in avoiding unnecessary antibiotics following his own experience with antibiotic resistant infections. He reviewed and commented on subsequent versions of the full manuscript.

\section{How this article was created}

We searched Medline and the Cochrane Library to identify published randomised controlled trials and systematic reviews on effective strategies to promote judicious use of antibiotics for respiratory tract infection (RTI) in primary care. We reviewed the available published evidence with the aim of developing a standardised approach that incorporates the new reality of covid-19. When evidence was lacking, we relied on expert opinion through broad consultation with experts in family medicine, primary care, infectious diseases and pharmacy. A dedicated toolkit to support Canadian primary care providers is available here: https://choosingwiselycanada.org/perspective/the-cold-standard/

Contributorship and the guarantor: IL conceptualised the article, conducted the initial literature review and prepared the first draft of the article, and led subsequent revisions. KB conducted further reviews of the literature and revised subsequent drafts of the manuscript. JL, GT, OO, and AG contributed to the development of table 1. KB, GT, OO, AG, and BJ reviewed and revised the manuscript. JL is the guarantor.

Acknowledgments: The authors would like to thank the following individuals who contributed to the development of the Choosing Wisely Canada Cold Standard toolkit: Kimberly Wintemute, Jeremy Grimshaw, Andrea Patey, Michael Zahradnik, Sameh Martazhejri, James Brooks, Jacqueline Arthur, Wendy Levinson, Andre Girouard, Doreen Day, Stephanie Callan, and Joanna Wong.

Provenance and peer review: commissioned, based on an idea from the author; externally peer reviewed. This article is the first in a series of Education articles based on recommendations from international Choosing Wisely campaigns. Choosing Wisely had no input into the peer review process or editorial decision. The BMJ thanks Wendy Levinson and Karen Born for valuable advice and supporting the selection of topics.

Competing interests The BMJ has judged that there are no disqualifying financial ties to commercial companies. The authors declare the following other interests: none.

Further details of The BMJ policy on financial interests are here: https://www.bmj.com/about-bmj/resources-authors/forms-policies-and-checklists/declaration-competing-interests

1 Dolk FCK, Pouwels KB, Smith DRM, Robotham JV, Smieszek T. Antibiotics in primary care in England: which antibiotics are prescribed and for which conditions?] Antimicrob Chemother 2018;73(suppl_2):ii2-10. doi: 10.1093/jac/dkx504 pmid: 29490062

2 Greenhalgh T, Koh GCH, Car J. Covid-19: a remote assessment in primary care. BMJ 2020;368:m1182. doi: 10.1136/bmj.m1182 pmid: 32213507

3 Tenforde MW, Billig Rose E, Lindsell C), etalCDC COVID-19 Response Team. Characteristics of adult outpatients and inpatients with covid-19-11 academic medical centers, United States, March-May 2020. MMWR Morb Mortal Wkly Rep 2020;69:841-6. doi: 10.15585/mmwr.mm6926e3 pmid: 32614810

4 Langford BJ, So M, Raybardhan S, etal. Bacterial co-infection and secondary infection in patients with COVID-19: a living rapid review and meta-analysis. Clin Microbiol Infect 2020;20:30423-7.

5 Le Saux N, Robinson JLCanadian Paediatric Society, Infectious Diseases and Immunization Committee. Management of acute otitis media in children six months of age and older. Paediatr Child Health 2016;21:39-50. doi: 10.1093/pch/21.1.39 pmid: 26941560
6 Fine AM, Nizet V, Mandl KD. Large-scale validation of the Centor and Mclsaac scores to predict group A streptococcal pharyngitis. Arch Intern Med 2012;172:847-52. doi: 10.1001/archinternmed.2012.950 pmid: 22566485

7 Rosenfeld RM, Piccirillo JF, Chandrasekhar SS, etal. Clinical practice guideline (update): Adult Sinusitis Executive Summary. Otolaryngol Head Neck Surg 2015;152:598-609. doi: 10.1177/0194599815574247 pmid: 25833927

8 Chow AW, Benninger MS, Brook I, etal. Executive summary: IDSA clinical practice guideline for acute bacterial rhinosinusitis in children and adults. Clin Infect Dis 2012;54:1041-5doi: 10.1093/cid/cir1043.

9 Hill AT, Gold PM, El Solh AA, Metlay JP, Ireland B, Irwin RSCHEST Expert Cough Panel. Adult outpatients with acute cough due to suspected pneumonia or influenza: CHEST guideline and expert panel report. Chest 2019;155:155-67. doi: 10.1016/j.chest.2018.09.016 pmid: 30296418

10 Choosing Wisely Canada. The cold standard: how to care for ambulatory patients with respiratory tract infections: a revised toolkit for using antibiotics wisely in the era of covid-19 and virtual care. 2020 https://www.cfpc.ca/CFPC/media/PDF/The-Cold-Standard-UAW_V2_EN.pdf

11 Stamenova V, Agarwal P, Kelley L, etal. Uptake and patient and provider communication modality preferences of virtual visits in primary care: a retrospective cohort study in Canada. BMJ Open 2020;10:e037064. doi: 10.1136/bmjopen-2020-037064 pmid: 32636284

12 Ray KN, Shi Z, Gidengil CA, Poon SJ, Uscher-Pines L, Mehrotra A. Antibiotic prescribing during pediatric direct-to-consumer telemedicine visits. Pediatrics 2019;143:e20182491. doi: 10.1542/peds.2018-2491 pmid: 30962253

13 Uscher-Pines L, Mulcahy A, Cowling D, Hunter G, Burns R, Mehrotra A. Access and quality of care in direct-to-consumer telemedicine. Telemed J E Health 2016;22:282-7. doi: 10.1089/tmj.2015.0079 pmid: 26488151

14 McKay R, Mah A, Law MR, McGrail K, Patrick DM. Systematic review of factors associated with antibiotic prescribing for respiratory tract infections. Antimicrob Agents Chemother 2016;60:4106-18. doi: 10.1128/AAC.00209-16 pmid: 27139474

15 Linder JA, Singer DE, Stafford RS. Association between antibiotic prescribing and visit duration in adults with upper respiratory tract infections. Clin Ther 2003;25:2419-30. doi: 10.1016/S0149-2918(03)80284-9 pmid: 14604741

16 Keesara S, Jonas A, Schulman K. Covid-19 and health care's digital revolution. N Engl J Med 2020;382:e82. doi: 10.1056/NEJMp2005835 pmid: 32240581

17 Mangione-Smith R, McGlynn EA, Elliott MN, Krogstad P, Brook RH. The relationship between perceived parental expectations and pediatrician antimicrobial prescribing behavior. Pediatrics 1999;103:711-8. doi: 10.1542/peds.103.4.711 pmid: 10103291

18 McNulty CAM, Collin SM, Cooper E, Lecky DM, Butler CC. Public understanding and use of antibiotics in England: findings from a household survey in 2017. BMJ Open 2019;9:e030845. doi: 10.1136/bmjopen-2019-030845 pmid: 31662380

19 Spurling GKP, Del Mar CB, Dooley L, Foxlee R, Farley R. Delayed antibiotic prescriptions for respiratory infections. Cochrane Database Syst Rev 2017;9:CD004417.pmid: 28881007

20 Lee C, Jafari M, Brownbridge R, Phillips C, Vanstone JR. The viral prescription pad - a mixed methods study to determine the need for and utility of an educational tool for antimicrobial stewardship in primary health care. BMC Fam Pract 2020;21:42. doi: 10.1186/s12875-020-01114-z pmid: 32087685

21 Coxeter P, Del Mar CB, McGregor L, Beller EM, Hoffmann TC. Interventions to facilitate shared decision making to address antibiotic use for acute respiratory infections in primary care. Cochrane Database Syst Rev2015;11:CD010907. doi: 10.1002/14651858.CD010907.pub2 pmid: 26560888

This article is made freely available for use in accordance with BMJ's website terms and conditions for the duration of the covid-19 pandemic or until otherwise determined by BMJ. You may use, download and print the article for any lawful, non-commercial purpose (including text and data mining) provided that all copyright notices and trade marks are retained. 